Letter

\title{
Landslide Displacement Monitoring with Split- Bandwidth Interferometry: A Case Study of the Shuping Landslide in the Three Gorges Area
}

\author{
Xuguo Shi ${ }^{1} \mathbb{B}^{\mathbb{D}}$, Houjun Jiang ${ }^{2, *}$, Lu Zhang ${ }^{3,4, *}$ and Mingsheng Liao ${ }^{3,4}$ \\ 1 Faculty of Information Engineering, China University of Geosciences, 388 Lumo Road, Wuhan 430074, \\ China; shixg@cug.edu.cn \\ 2 Department of Surveying and Geoinformatics, Nanjing University of Posts and Telecommunications, \\ 9 Wenyuan Road, Nanjing 210023, China \\ 3 State Key Laboratory of Information Engineering in Surveying, Mapping and Remote Sensing, \\ Wuhan University, 129 Luoyu Road, Wuhan 430079, China; liao@whu.edu.cn \\ 4 Collaborative Innovation Center for Geospatial Technology, 129 Luoyu Road, Wuhan 430079, China \\ * Correspondence: jianghouj@njupt.edu.cn (H.J.); luzhang@whu.edu.cn (L.Z.)
}

Academic Editors: Salvatore Stramondo and Prasad S. Thenkabail

Received: 3 August 2017; Accepted: 8 September 2017; Published: 10 September 2017

\begin{abstract}
Landslides constitute a major threat to people's lives and property in mountainous regions such, as in the Three Gorges area in China. Synthetic Aperture Radar Interferometry (InSAR) with its wide coverage and unprecedented displacement measuring capabilities has been widely used in landslide monitoring. However, it is difficult to apply traditional InSAR techniques to investigate landslides having large deformation gradients or moving primarily in north-south direction. In this study, we propose a time series split-bandwidth interferometry (SBI) procedure to measure two dimensional (azimuth and range) displacements of the Shuping landslide in the Three Gorges area with 36 TerraSAR-X high resolution spotlight (HS) images acquired from February 2009 to April 2010. Since the phase based SBI procedure is sensitive to noise, we focused on extracting displacements of corner reflectors (CRs) installed on or surrounding the Shuping landslide. Our results agreed well with measurements obtained by the point-like targets offset tracking (PTOT) technique and in-situ GPS stations. Centimeter level accuracy could be achieved with SBI on CRs which shows great potential in futures studies on fast moving geohazards.
\end{abstract}

Keywords: landslide; the Three Gorges; corner reflector; split-bandwidth interferometry

\section{Introduction}

A landslide refers to the movement of rock, earth, and debris downward upon a slope which may be caused by natural factors or human activities [1]. As a prevalent geohazard in mountainous areas, it poses a serious danger to local residents. Thus, continuous monitoring of landslide activity in these areas is essential to ensure public safety.

According to investigations, the Three Gorges area is frequently affected by landslide hazards, and there have been more than 3800 reported landslides [2]. Serving the largest hydro-power station in China, the Three Gorges Dam began construction in 1994 and it was completed in 2006. Presently, the water level varies between $145 \mathrm{~m}$ and $175 \mathrm{~m}$ according to the dam's operation scheme. The annual water level fluctuation contributed much to the destabilization of bank slopes along the Yangtze River which can inevitably aggravate geohazards such as landslides and rock falls.

SAR interferometry (InSAR) can be used as an earth displacement monitoring tool, having the advantages of wide area coverage and high accuracy; it has been widely used in previous landslide 
monitoring [3-7] studies. The dense vegetation in the Three Gorges area causes serious decorrelation which is unfavorable for InSAR analysis [8]. To overcome this problem, several corner reflectors (CRs) were installed on a few well-known landslides to improve the performance of differential InSAR [8,9]. Incidentally, it should be noted that the applicability of differential InSAR are seriously limited for landslides without CRs installed. Thus, advanced InSAR methods such as persistent scatters SAR interferometry (PSI) [1,10-12], Quasi Permanent Scatterers (QPS) InSAR [13] and Small baselines subset (SBAS) InSAR $[3,14]$ which mainly make use of point-like scatterers have also been applied to identify and monitor active landslides in this area. Generally, if displacement between neighboring pixels exceed $1 / 4$ of the wavelength, an unavoidable phase unwrapping error will cause underestimation [6], especially in densely vegetated areas, and this error should be mitigated.

In the Three Gorges area, there are many active landslides with annual displacement rates of meter-level [15]. Thus, the effectiveness of the InSAR method when applied to monitoring these landslides with large deformation gradients will be significantly reduced. In such cases, one solution is to employ the pixel offset tracking method to track the displacements that have occurred in the azimuth and range directions using amplitude information of the SAR images. This technique has been successfully applied to monitor the Shuping landslide [16-19] and the Kaziwan landslide [19] in the Three Gorges area. Meanwhile, the split-bandwidth interferometry (SBI), which is also known as multi-aperture interferometry (MAI), can also measure large azimuth displacements by analyzing forward and backward single look complex SAR images with centimeter-level accuracy [20-22]. Usually, this method is applied to obtain the displacements in the azimuthal direction. However, SBI can also be used in the range direction although this is comparatively rare because of the low sensitivity to displacements compared with standard InSAR methods, as well as a high sensitivity to pixel's signal to cluster ratio (SCR) [23]. Nevertheless, phase unwrapping errors will occur with standard InSAR methods, especially when measuring rapid movements on sparse points. In contrast, the characteristic of having low sensitivity to displacements for SBI becomes an advantage when measuring landslide deformations of large gradient [23]. As a result, unwrapping errors in the traditional InSAR method might be greatly suppressed.

In this study, using high resolution TerraSAR-X SAR images, split-bandwidth interferometry in the azimuth and range directions were applied to retrieve two-dimensional time series displacements of CRs installed on the Shuping landslide, located in the Three Gorges area. The effectiveness of our method was validated against results obtained from point-like targets offset tracking in a previous study [16] and Global Positioning System (GPS) measurements. This study is organized as follows: Section 2 describes our study area and datasets, and the principles of our method are elaborated in Section 3. Our results were given and evaluated in Section 4 , followed by study conclusions.

\section{Study Areas and Datasets}

\subsection{The Shuping Landslide}

The first impoundment of the Three Gorges dam in 2003 activated many ancient landslides such as the Qianjiangping landslide [24], the Shuping landslide [25] etc. The Shuping landslide is located at the south bank of Yangtze River as shown in Figure 1a. The possible catastrophic failure of the Shuping landslide may pose great threats to the safety of local marine transportation and infrastructure. Thus, the movement status of the slope has drawn significant concern. GPS stations were promptly installed on the Shuping landslide for ongoing monitoring of the slope evolution [25]. InSAR methods have also been employed to monitor the displacement of the Shuping landslide [26]. As we can see from Figure $1 b$, the Shuping landslide is covered by dense vegetation. This results in a significant loss of coherence hindering the application of InSAR. Thus, triangular trihedral corner reflectors (CRs) with edges of 1 meter were installed on the Shuping landslide to assist InSAR-based landslide displacement monitoring [8,9]. Readers may refer to [8] for detailed design specifications of the CRs in the Three Gorges area. Generally, the radar cross section of the CR can reach more than $20 \mathrm{~dB}$, which can be 
easily identified in vegetated areas [8]. The locations of CRs installed on or surrounding the Shuping landslide are marked with red dots in Figure $1 \mathrm{~b}$.

Previous studies with standard InSAR failed because of the rapid displacement of the Shuping landslide [3]. As an alternative method, SAR pixel offset tracking analysis has been successfully employed to obtain the displacements of the Shuping landslide using high resolution TerraSAR-X datasets [16,17]. Here, we explored the feasibility of phase based SBI for monitoring rapid movements in azimuth and range directions.

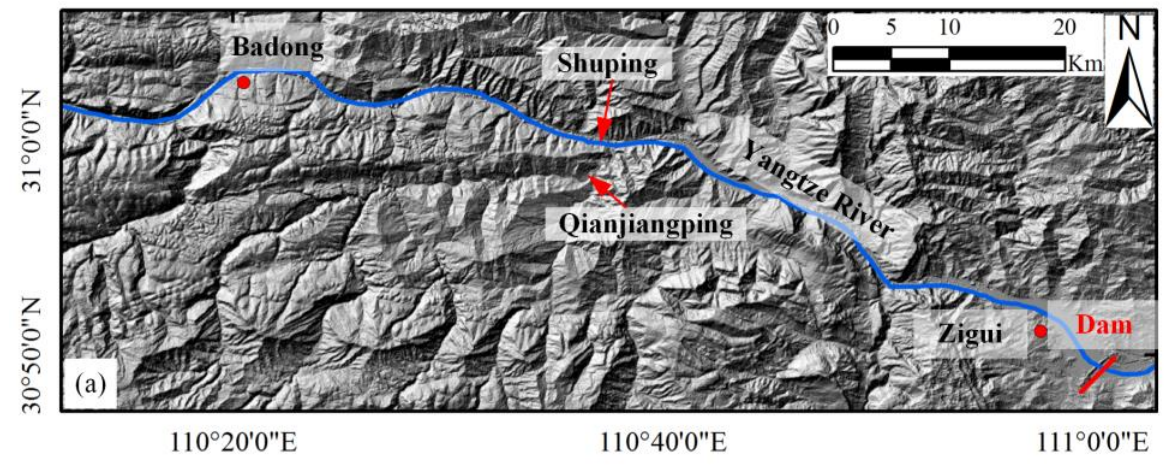

(a)

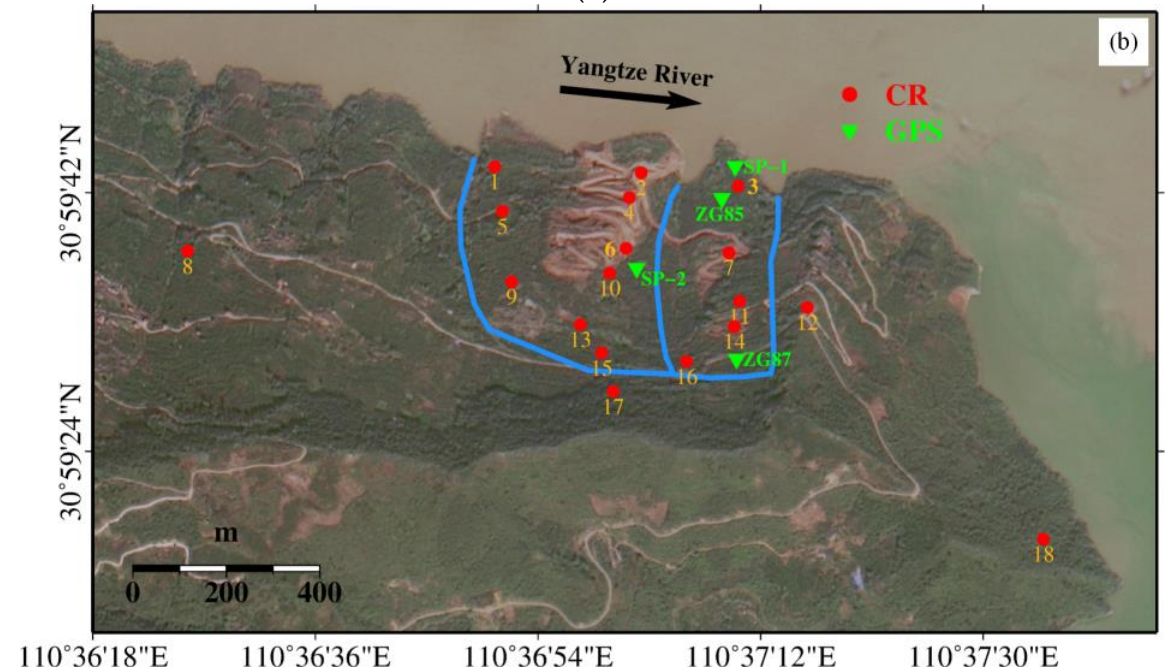

(b)

Figure 1. (a) Location of the Shuping landslide; (b) Location of corner reflectors and GPS stations installed on the Shuping landslide overlaid on ZY-3 satellite multispectral optical image.

\subsection{Datasets}

There were 36 TerraSAR-X High resolution Spotlight (HS) images from February 2009 to April 2010 that were acquired to monitor the movement of shuping landslide. Basic parameters of the dataset are summarized in Table 1. According to our previous study, very minor displacements of Shuping landslide occurred during winter when the water level of the Three Gorges Reservoir remained relatively stable and precipitation was low [16]. Thus, the image acquired in 12 November 2009 during this period with maximum correlation with other SAR images was selected as a common master for time series analysis. The temporal and perpendicular baseline distributions are given in Figure 2. A SRTM DEM with approximately $30 \mathrm{~m}$ resolution was used for DEM assisted registration and geocoding. Horizontal displacements measured by 4 GPS stations, namely SP-1, SP-2, ZG85 and ZG87, are collected for validation. The locations of these GPS stations are marked by green triangles in Figure 1b. 
Table 1. Basic information for high resolution spotlight TerraSAR-X datasets.

\begin{tabular}{cc}
\hline Parameters & Values \\
\hline Orbit direction & Descending \\
Look angle $\left(^{\circ}\right)$ & 39 \\
Heading $\left(^{\circ}\right)$ & 189.6 \\
Polarization & $\mathrm{HH}$ \\
Azimuth spacing $(\mathrm{m})$ & 0.87 \\
Range spacing $(\mathrm{m})$ & 0.45 \\
Range Bandwidth $(\mathrm{MHz})$ & 300 \\
Azimuth Bandwidth $(\mathrm{Hz})$ & 7277 \\
\hline
\end{tabular}

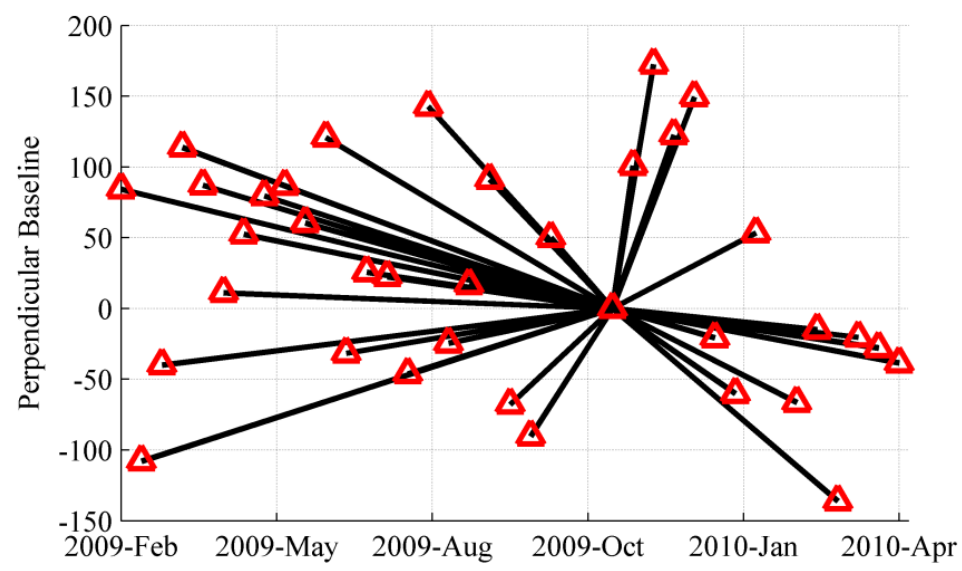

Figure 2. Temporal and perpendicular baseline distributions.

\section{Time Series Displacement Retrieval Methods}

\subsection{Split-Bandwidth Interferometry}

Split-bandwidth interferometry estimates pixel shifts between two single-look complex (SLC) SAR images by measuring phase differences of two interferograms formed by using lower and upper portions of imaging spectrum separately. Since the impulse response of a SAR system has a linear phase variation within its main lobe depending on the signal's center frequency $f_{c}$, a pixel offset $\Delta t$ in seconds will lead to an additional phase term $2 \pi f_{c} \Delta t$ in standard InSAR, mixed with interferometric phases containing topography, atmospheric delay, and displacement [27]. The pixel shift can be extracted by performing a phase differential operation between two interferograms from the same image pair with different azimuth or range center frequencies but identical interferometric phases.

In this study, we implement SBI as follows: a pair of TerraSAR-X HS images $m$ and $s$ are split into four low-resolution sublook images $m_{l}, m_{u}, s_{l}$, and $s_{u}$ by filtering out the lower and upper bands in the frequency domain. Then, by combining the sublook images with common spectra, two interferograms are formed and their phase difference $\phi_{\text {split }}$ is derived from $\left(m_{u} \cdot s_{u}^{*}\right)\left(m_{l} \cdot s_{l}^{*}\right)^{*}$, where ${ }^{*}$ indicates conjugate multiplication. Finally, the pixel shift $\Delta t$ in units of time can be retrieved from the phase difference $\phi_{\text {split }}$, given the spectral separation $\Delta f_{c}$ between the two sublook images [27]:

$$
\Delta t=\frac{\phi_{\text {split }}}{2 \pi \Delta f_{c}}
$$

In the case of range SBI, the phase difference $\phi_{\text {split }}$ contains a component corresponding to the range offsets produced by topography and the InSAR baseline. This component should be removed by using the DEM-assisted co-registration $[28,29]$. DEM and orbit ephemerides are used in conjunction to calculate the topographic offsets. In the azimuth case, little topographic information remains in $\phi_{\text {split }}$ because the azimuth offsets are insensitive to the cross-track baseline. 
For the TerraSAR-X HS image, a larger spectral separation of sublooks can be achieved compared to the image acquired in Stripmap Mode (SM), dramatically improving the sensitivity and accuracy of SBI. According to Equation (1), the sensitivities to ground displacements for one cycle of $\phi_{\text {split }}$ are $\sim 0.75 \mathrm{~m}$ and $\sim 1.46 \mathrm{~m}$ for range and azimuth split-bandwidth interferometry respectively. Because of the finer bandwidth increment, the sensitivity of using TerraSAR-X HS image is approximately 3 times that of the SM image.

SBI is equivalent to coherent cross correlation (CCC), the maximum likelihood estimator for the pixel offset between distributed Gaussian targets. Since the requirement of removing interferometric phase complicates the implementation of CCC, SBI is often used as a replacement in practice. In theory, the standard deviation in displacement estimation from the SBI is given by [30]:

$$
\sigma=\frac{1}{2 \pi \Delta f_{c}} \frac{1}{\sqrt{N}} \sqrt{\frac{B}{b}} \frac{\sqrt{1-\gamma^{2}}}{\gamma} \frac{p_{s p a}}{\Delta t_{s}}
$$

where $\Delta f_{c}=B-b, B$ is the processed bandwidth of a single target, $b$ is the sublook bandwidth which is often selected as one third of the bandwidth [30,31], $N$ is the number of independent samples averaged, $\gamma$ is the interferometric coherence, $\Delta t_{s}$ is the image sampling in seconds, and $p_{s p a}$ is the pixel spacing. In order to improve the reliability of SBI measurements, pixels exhibiting the same point-like behaviors as the center pixel were selected first using a two-sample KS test within an estimation window of 64 pixels in azimuth and 32 pixels in range. Then, adaptive multi-looking was carried out on these pixels. In our case, it is easy to find more than 10 point-like behaved pixels since the side lobe is very obvious for such high resolution TerraSAR-X HS images. For a TerraSAR-X HS image, $B$ is $300 \mathrm{MHz}$ in range and $7277 \mathrm{~Hz}$ in azimuth. Assuming $\gamma=0.95$ on CRs, then $N=10$ and $b=B / 3, \sigma$ is $\sim 2.1 \mathrm{~cm}$ and $\sim 3.8 \mathrm{~cm}$ in range and azimuth directions respectively.

The workflow of our process is shown in Figure 3. Split-bandwidth interferograms were first generated with the method described above. After pairwise azimuth and range SBI were performed, the corresponding phases of the CRs can then be extracted. As mentioned before, the phase components from topography and baseline have been removed. Thus, three dimensional phase unwrapping [32] can be carried out directly to retrieve the time series displacements.

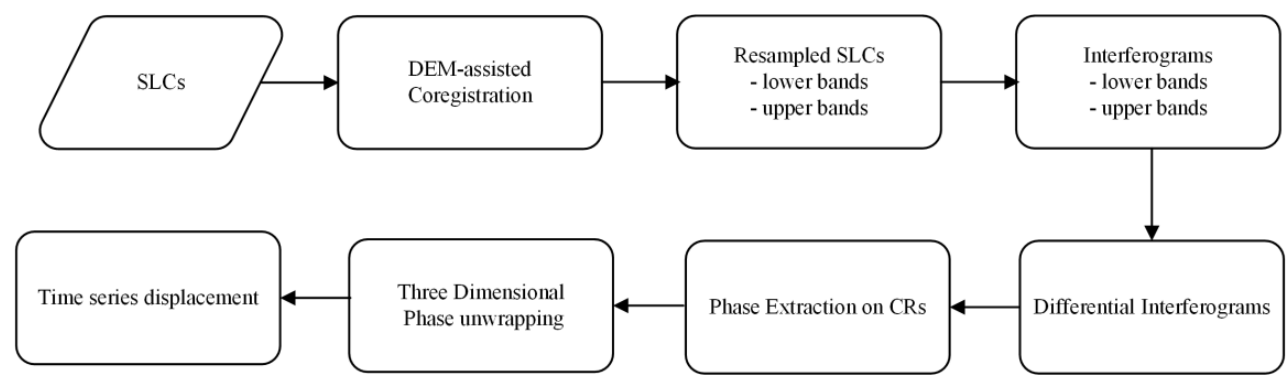

Figure 3. Diagram of Split-Bandwidth Interferometry process.

\subsection{Point-Like Targets Offset Tracking}

Rapidly moving ground targets might lead to loss of coherence or phase unwrapping problems which greatly affect the applicability of standard InSAR. In such situations, a pixel offset tracking method can also be used to extract azimuth and range displacement from the amplitude information using high resolution SAR images. In our study, point-like targets offset tracking (PTOT) making use of pixels with high amplitude values are employed to track the movements of the CRs. PTOT mainly makes use of pixels with high amplitude values. Usually, high SCRs will be maintained on these pixels to ensure greater accuracy of our measurements. Readers can find a detailed workflow of PTOT in our previous study [16]. Here, the PTOT results are used for cross validation with SBI. The theoretical accuracy of amplitude pixel offset tracking on point-like targets can be expressed as [30,33]: 


$$
\sigma=\frac{\sqrt{3}}{\pi} \frac{1}{\sqrt{S C R}} p_{\text {spa }}
$$

where SCR is the signal to cluster ratio of output correlation for point-like targets and $p_{\text {spa }}$ is the pixel spacing. In our case, the typical value of SCR for CRs are more than 150 (corresponding to $21 \mathrm{~dB}$ ). Thus, the achievable accuracy can be better than 0.045 pixels corresponding to $\sim 2 \mathrm{~cm}$ and $\sim 4 \mathrm{~cm}$ in the range and azimuth directions separately for high resolution TerraSAR-X spotlight datasets, which is very close to the theoretical accuracy of SBI, as we discussed above.

\section{Results and Discussions}

\subsection{Comparsion of Time Series Displacements from SBI and PTOT}

As shown in Figure 1b, there were four CRs installed surrounding Shuping landslide. In order to mitigate systematic biases, CR12 was selected as a reference to calibrate the measurements of other CRs. Time series displacements measured by the SBI and PTOT methods in both azimuth and range directions for the other three CRs, namely CR8, CR17 and CR18, are given in Figure 4. Corresponding statistics of these three CRs are given in Table 2. Overall, good agreement was achieved for the measurements from both methods. As expected, all three of these CRs were stable during the period of more than one year.

Since CRs are ideal point-like targets, very high SCRs can be maintained over a long period. As mentioned in Section 3, the theoretical achievable accuracy from the PTOT method is almost the same as that from the SBI method in both azimuth and range directions on CRs. As expected, the statistics in Table 2 suggest that comparable accuracy was achieved by the SBI and PTOT in both azimuth and range direction. Statistics on these data indicate that the achievable accuracy can reach centimeter-level on point-like targets. At the same time, the mean and standard deviation of measurements in the range direction are lower than in the azimuth direction for both methods. This can be explained by the fact that the pixel spacing in the range direction are much higher than that in the azimuth direction. The standard deviations from SBI measurements are relatively higher than that from PTOT measurements, which means the consistency of PTOT measurements are relatively better than that of SBI measurements. This could be attributed to the higher sensitivity of noise for SBI. In our case, noise induced by vegetation or geometrical distortions in the mountainous setting can be very serious.

Furthermore, we notice that the differences between SBI and PTOT measurements on a few CRs, e.g., CR18 in Figure 4 and CR7, CR11 in Figures 5 and 6, are higher than other CRs. Signals from the target's surroundings such as vegetation in the resolution cell, e.g., CR18 lying in layover areas, might affect the accuracy of SBI measurements. Multi-looking of the SBI process also plays an important role in the measurement accuracy. Since CRs are ideal point-like targets, it is difficult to find enough point-like targets for adaptive multi-looking. Time series displacements of $14 \mathrm{CRs}$ installed on Shuping landslide measured with SBI and PTOT in azimuth and range directions were shown in Figures 5 and 6, respectively. As expected, very good agreements were achieved at all CRs in both azimuth and range directions with only minor disparities between SBI measurements and PTOT measurements identified. Due to the higher sensitivity in the range direction compared with the azimuth direction for both methods, a higher consistency of time series measurements in the range direction was achieved. Similar displacement patterns with different magnitudes were identified on CRs which is mainly caused by the decline of water level in the Three Gorges area [16]. The most significant displacements in azimuth direction and range direction reached nearly $0.9 \mathrm{~m}$ on CR11 and nearly $0.7 \mathrm{~m}$ on CR14, respectively, during a period of over one year. Both CRs are located on the top of the Shuping landslide. The large displacements are mainly concentrated in the eastern and central part of Shuping landslide. Very small displacements detected on the western part of Shuping landslide where CR1, CR5 and CR9 are located indicate that this part might be stable. 

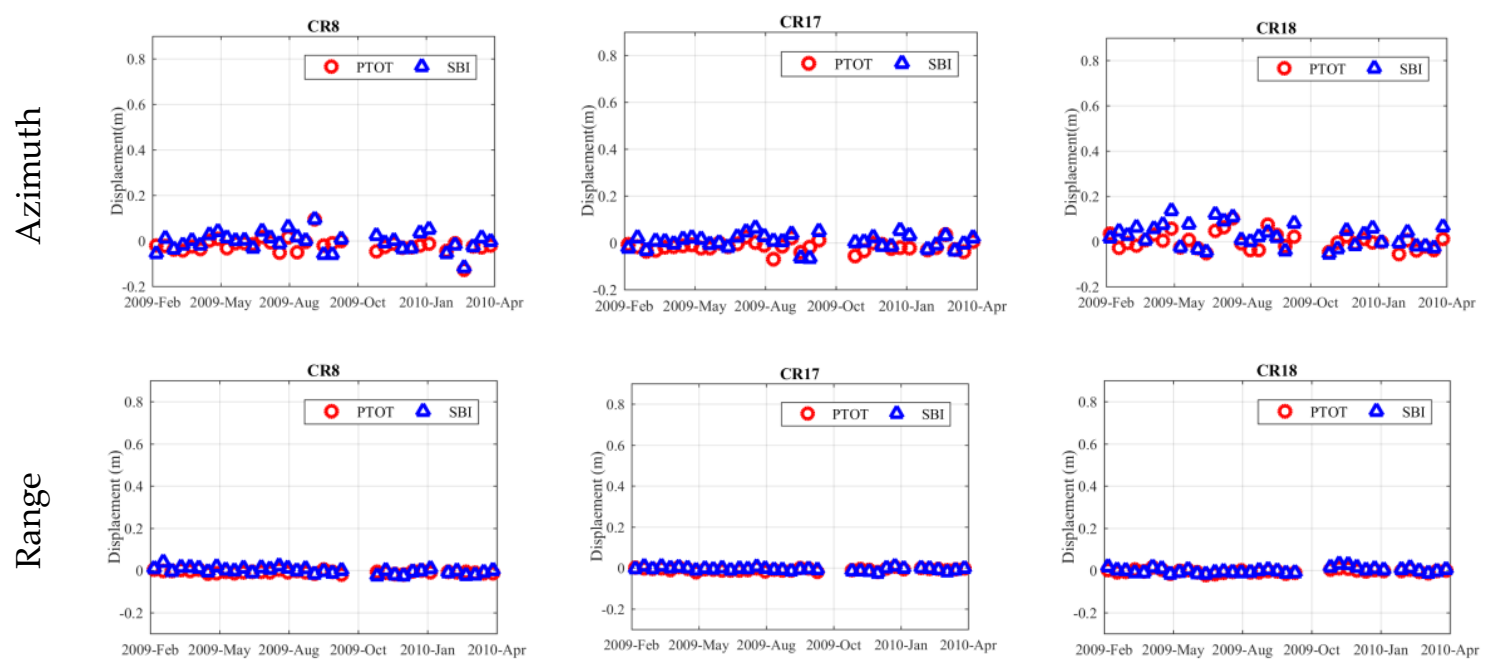

Figure 4. Comparison of displacement measurements at stable Corner reflectors (CRs) by Split-bandwidth interferometry (SBI) and point-like targets offset tracking (PTOT) in azimuth and range directions.

Table 2. Basic statistics of stable CRs outside Shuping landslide (unit: $\mathrm{cm}$ ).

\begin{tabular}{ccccccccc}
\hline & \multicolumn{4}{c}{ SBI } & \multicolumn{4}{c}{ PTOT } \\
\cline { 2 - 9 } CR & \multicolumn{2}{c}{ Azimuth } & \multicolumn{2}{c}{ Range } & \multicolumn{2}{c}{ Azimuth } & \multicolumn{2}{c}{ Range } \\
\cline { 2 - 9 } & Mean & STD & Mean & STD & Mean & STD & Mean & STD \\
\hline CR8 & -0.4 & 4.1 & -0.1 & 1.4 & -1.9 & 3.3 & -0.8 & 0.7 \\
CR17 & 0.5 & 2.3 & 0.6 & 0.8 & -1.5 & 2.1 & -0.4 & 0.6 \\
CR18 & 2.5 & 5.0 & 0.0 & 1.2 & 0.2 & 3.8 & -0.8 & 0.9 \\
\hline
\end{tabular}

\subsection{Valadation with GPS Measurments}

To further validate our results, comparisons between GPS observations and SAR measurements from SBI and PTOT were also carried out. As mentioned in Section 2, only the easting and northing components of GPS measurements are available. Thus, GPS measurements were converted into SAR azimuth geometry which is not considered sensitive to displacements in the vertical direction for the simplicity of validation.

$$
D_{\mathrm{AZ}}=D_{\mathrm{N}} \cos \alpha+D_{\mathrm{E}} \sin \alpha
$$

where $D_{\mathrm{AZ}}, D_{\mathrm{N}}$ and $D_{\mathrm{E}}$ are displacements in SAR azimuth direction, northing and easting directions respectively. $\alpha$ is the heading angle of the satellite at the target point. All the measurements from 4 GPS stations were initially calibrated with respect to the measurement obtained at 10 November 2009 that is closest to the master image of TerraSAR-X dataset.

The locations of CRs and GPS stations are not identical, as shown in Figure 1b. According to the first law of geography, the variation of displacement magnitude will be generally limited within a small area. Thus, validations between measurements from GPS stations and nearby CRs were carried out. Comparisons of CR and GPS pairs CR3 and SP-1, CR3 and ZG85, CR6 and SP2, CR10 and SP-2 as well as CR16 and ZG87 were given in Figure 7. The length of error bar for the GPS measurements is $10 \mathrm{~cm}$. The displacement pattern of the GPS and CR time series measurements are shown to be similar. Specific magnitude of time series displacements for CR3 and SP-1, CR3 and ZG85 as well as CR6 and SP-2 agreed quite well. All the measurements from SBI and PTOT method are distributed within the error bars. However, disparities between GPS stations and SAR measurements were more apparent with the increased distance as shown for CR10 and SP-2, CR16 and ZG87. These disparities are unavoidable for the Shuping landslide with non-uniform displacements. Nevertheless, we can conclude that both the SBI and PTOT methods can achieve centimeter-level accuracy on point-like targets. 

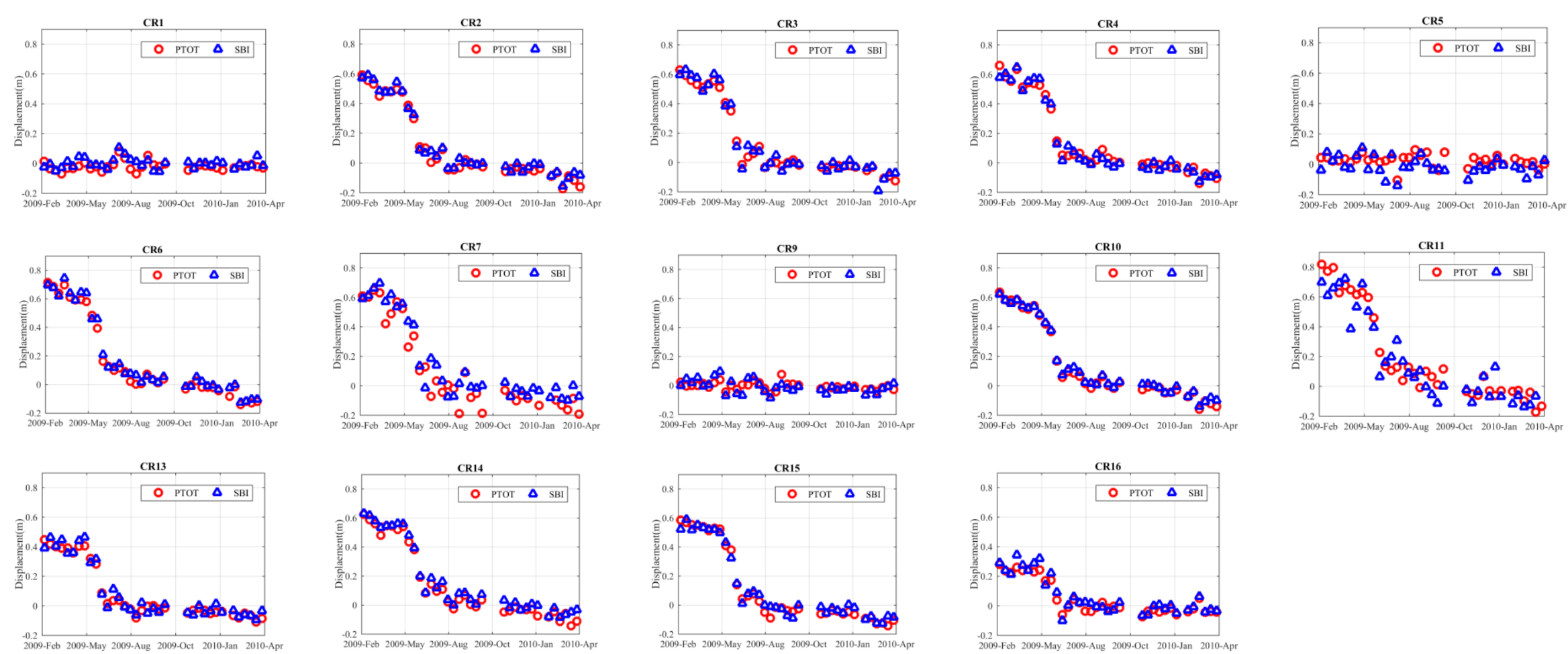

Figure 5. Comparison of time series displacements of CRs at Shuping landslide in azimuth direction obtained by PTOT and SBI method. 

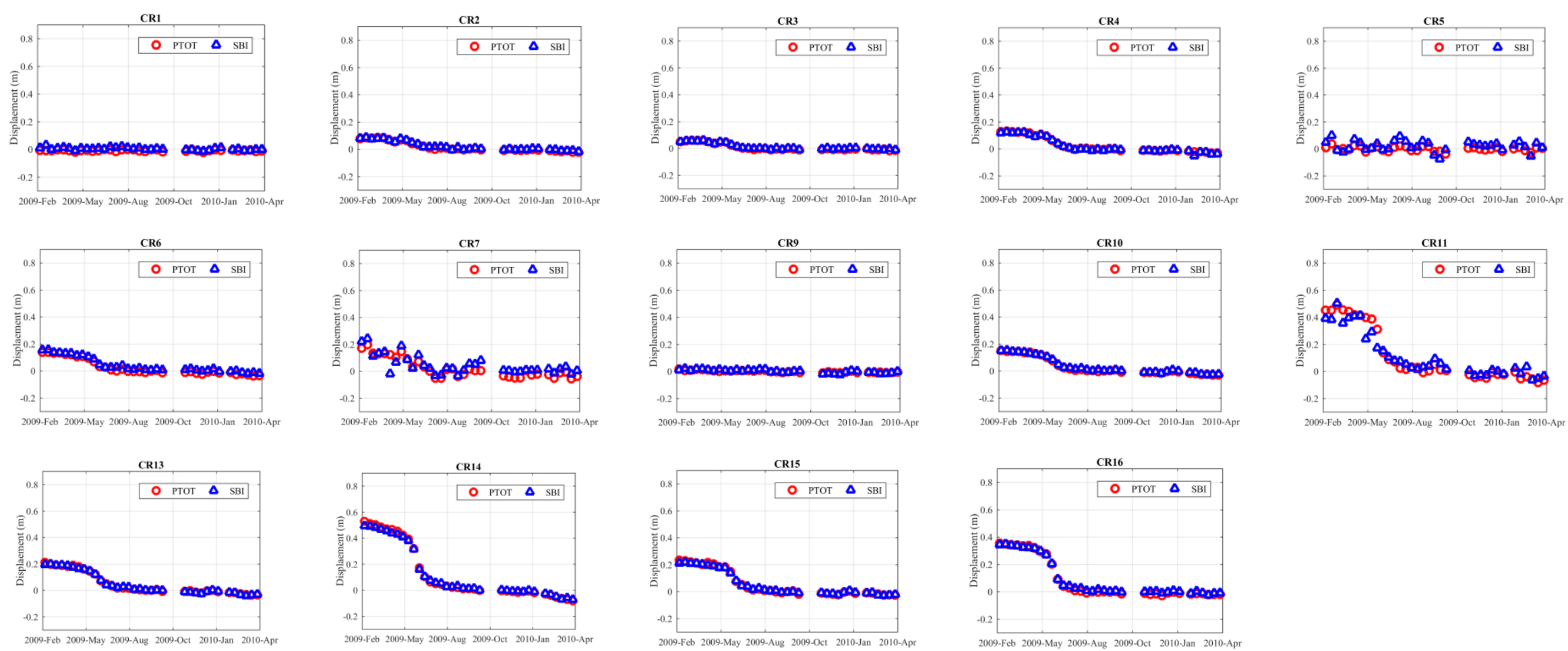

Figure 6. Comparison of time series displacements of CRs on Shuping landslide in range direction obtained by PTOT and SBI method 

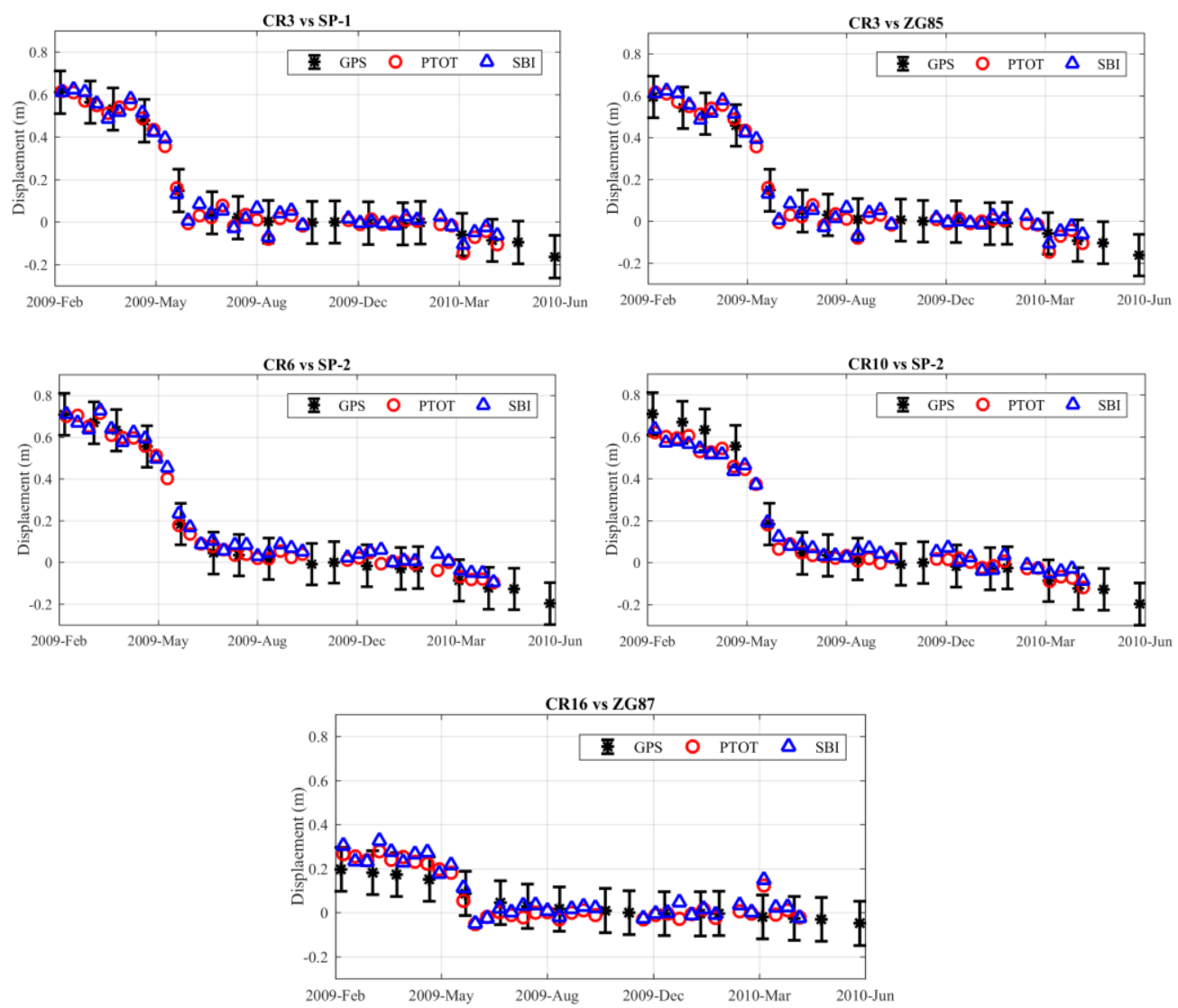

Figure 7. Comparison of measured displacements from SBI, PTOT and adjacent GPS stations in the azimuth direction. The length of the error bar is $10 \mathrm{~cm}$.

\section{Conclusions}

This study successfully employed the azimuth and range split-bandwidth interferometry to derive the two-dimensional time series displacements of CRs installed on or surrounding the Shuping landslide in the Three Gorges area. The results of our method was first validated with point-like targets offset tracking (PTOT) results from our previous study [16]. Then, comparisons with GPS measurements were carried out to evaluate the effectiveness of both the SBI and PTOT methodologies. Both methods can achieve centimeter-level accuracy on corner reflectors. Our study indicates that it is promising to employ both an azimuth and range SBI method to monitor rapid movement of ground targets. Meanwhile, the phase unwrapping problem for standard InSAR methodologies can also be significantly reduced. It is also worth noting that the multi-look process should be carried out for natural targets, such as exposed rocks, to improve the performance of SBI. Thus, the theoretical achievable accuracy for the SBI method can demonstrate a better performance than the pixel offset tracking method on natural targets [21]. This method can be employed to monitor fast moving landslides with sparse vegetation coverage, such as the Guobu slope in Qinghai Province, China [34].

Acknowledgments: This work was financially supported by the National Key R\&D Program of China (Grant No. 2017YFB0502700), the National Natural Science Foundation of China (Grant No. 61331016, 41702376, 41774006 and 41501497), Fundamental Research Funds for the Central Universities, China University of Geosciences (Wuhan) (Grant No. CUG170634), NUPTSF (Grant No. NY214197). The TerraSAR-X datasets were provided by German Aerospace Center (DLR) through the TSX-Archive-2012 AO project (GEO1856).

Author Contributions: X.S., H.J., L.Z. and M.L. conceived and designed the experiments; X.S. performed the experiments; X.S., H.J. and L.Z. analyzed the results; X.S. and H.J. wrote original manuscript. L.Z. edited the manuscript. All authors have read and approved the final manuscript. 
Conflicts of Interest: The authors declare no conflict of interest.

\section{References}

1. Liao, M.; Tang, J.; Wang, T.; Balz, T.; Zhang, L. Landslide monitoring with high-resolution SAR data in the Three Gorges region. Sci. China Earth Sci. 2012, 55, 590-601. [CrossRef]

2. Liu, C.; Liu, Y.; Wen, M.; Li, T.; Lian, J.; Qin, S. Geo-hazard Initiation and Assessment in the Three Gorges Reservoir. In Landslide Disaster Mitigation in Three Gorges Reservoir, China; Wang, F., Li, T., Eds.; Springer: Berlin/Heidelberg, Germany, 2009; pp. 3-40.

3. Shi, X.; Liao, M.; Li, M.; Zhang, L.; Cunningham, C. Wide-Area Landslide Deformation Mapping with Multi-Path ALOS PALSAR Data Stacks: A Case Study of Three Gorges Area, China. Remote Sens. 2016, 8, 136. [CrossRef]

4. Zhao, C.; Lu, Z.; Zhang, Q.; de la Fuente, J. Large-area landslide detection and monitoring with ALOS/PALSAR imagery data over Northern California and Southern Oregon, USA. Remote Sens. Environ. 2012, 124, 348-359. [CrossRef]

5. Sun, Q.; Zhang, L.; Ding, X.L.; Hu, J.; Li, Z.W.; Zhu, J.J. Slope deformation prior to Zhouqu, China landslide from InSAR time series analysis. Remote Sens. Environ. 2015, 156, 45-57. [CrossRef]

6. Wasowski, J.; Bovenga, F. Investigating landslides and unstable slopes with satellite Multi Temporal Interferometry: Current issues and future perspectives. Eng. Geol. 2014, 174, 103-138. [CrossRef]

7. Abdolmaleki, N.; Motagh, M.; Bahroudi, A.; Sharifi, M.A.; Haghshenas Haghighi, M. Using Envisat InSAR time-series to investigate the surface kinematics of an active salt extrusion near Qum, Iran. J. Geodyn. 2014, 81, 56-66. [CrossRef]

8. Xia, Y.; Kaufmann, H.; Guo, X. Landslide monitoring in the Three Gorges area using D-InSAR and corner reflectors. Photogramm. Eng. Remote Sens. 2004, 70, 1167-1172.

9. Xia, Y.; Kaufmann, H.; Guo, X. Differential SAR interferometry using corner reflectors. In Proceedings of the IEEE International Geoscience and Remote Sensing Symposium, Toronto, ON, Canada, 24-28 June 2002; Volume 2, pp. 1243-1246.

10. Shi, X.; Zhang, L.; Liao, M.; Balz, T. Deformation monitoring of slow-moving landslide with L- and C-band SAR interferometry. Remote Sens. Lett. 2014, 5, 951-960. [CrossRef]

11. Wang, T.; Perissin, D.; Liao, M.; Rocca, F. Deformation monitoring by long term D-InSAR analysis in Three Gorges area, China. In Proceedings of the IEEE International Geoscience and Remote Sensing Symposium, Boston, MA, USA, 7-11 July 2008; pp. 65-68.

12. Tantianuparp, P.; Shi, X.; Zhang, L.; Balz, T.; Liao, M. Characterization of Landslide Deformations in Three Gorges Area Using Multiple InSAR Data Stacks. Remote Sens. 2013, 5, 2704-2719. [CrossRef]

13. Perissin, D.; Teng, W. Repeat-Pass SAR Interferometry with Partially Coherent Targets. IEEE Trans. Geosci. Remote Sens. 2012, 50, 271-280. [CrossRef]

14. Liu, P.; Li, Z.; Hoey, T.; Kincal, C.; Zhang, J.; Zeng, Q.; Muller, J.-P. Using advanced InSAR time series techniques to monitor landslide movements in Badong of the Three Gorges region, China. Int. J. Appl. Earth Obs. Geoinf. 2013, 21, 253-264. [CrossRef]

15. Miao, H.; Wang, G.; Yin, K.; Kamai, T.; Li, Y. Mechanism of the slow-moving landslides in Jurassic red-strata in the Three Gorges Reservoir, China. Eng. Geol. 2014, 171, 59-69. [CrossRef]

16. Shi, X.; Zhang, L.; Balz, T.; Liao, M. Landslide deformation monitoring using point-like target offset tracking with multi-mode high-resolution TerraSAR-X data. ISPRS J. Photogramm. Remote Sens. 2015, 105, 128-140. [CrossRef]

17. Singleton, A.; Li, Z.; Hoey, T.; Muller, J.P. Evaluating sub-pixel offset techniques as an alternative to D-InSAR for monitoring episodic landslide movements in vegetated terrain. Remote Sens. Environ. 2014, 147, $133-144$. [CrossRef]

18. Li, X.; Muller, J.; Chen, F.; Zhang, Y. Measuring displacement field from TerraSAR-X amplitude images by subpixel correlation: An application to the landslide in Shuping, Three Gorges Area. Acta Petrol. Sin. 2011, $27,3843-3850$.

19. Shi, X.; Liao, M.; Zhang, L.; Balz, T. Landslide stability evaluation using high-resolution satellite SAR data in the Three Gorges area. Q. J. Eng. Geol. Hydrogeol. 2016, 49, 203-211. [CrossRef] 
20. Hyung-Sup, J.; Joong-Sun, W.; Sang-Wan, K. An Improvement of the Performance of Multiple-Aperture SAR Interferometry (MAI). IEEE Trans. Geosci. Remote Sens. 2009, 47, 2859-2869. [CrossRef]

21. Bechor, N.B.; Zebker, H.A. Measuring two-dimensional movements using a single InSAR pair. Geophys. Res. Lett. 2006, 33, L16311. [CrossRef]

22. Jung, H.S.; Lu, Z.; Won, J.S.; Poland, M.P.; Miklius, A. Mapping Three-Dimensional Surface Deformation by Combining Multiple-Aperture Interferometry and Conventional Interferometry: Application to the June 2007 Eruption of Kilauea Volcano, Hawaii. Geosci. Remote Sens. Lett. 2011, 8, 34-38. [CrossRef]

23. Jiang, H.; Feng, G.; Wang, T.; Bürgmann, R. Toward full exploitation of coherent and incoherent information in Sentinel-1 TOPS data for retrieving surface displacement: Application to the 2016 Kumamoto (Japan) earthquake. Geophys. Res. Lett. 2017, 44. [CrossRef]

24. Wang, F.; Zhang, Y.; Huo, Z.; Peng, X.; Wang, S.; Yamasaki, S. Mechanism for the rapid motion of the Qianjiangping landslide during reactivation by the first impoundment of the Three Gorges Dam reservoir, China. Landslides 2008, 5, 379-386. [CrossRef]

25. Wang, F.; Zhang, Y.; Huo, Z.; Peng, X.; Araiba, K.; Wang, G. Movement of the Shuping landslide in the first four years after the initial impoundment of the Three Gorges Dam Reservoir, China. Landslides 2008, 5, 321-329. [CrossRef]

26. Xia, Y. CR-Based SAR-Interferometry for landslide monitoring. In Proceedings of the IEEE International Geoscience and Remote Sensing Symposium, Boston, MA, USA, 7-11 July 2008; Volume 2, pp. 1239-1242.

27. Scheiber, R.; Moreira, A. Coregistration of interferometric SAR images using spectral diversity. IEEE Trans. Geosci. Remote Sens. 2000, 38, 2179-2191. [CrossRef]

28. Sansosti, E.; Berardino, P.; Manunta, M.; Serafino, F.; Fornaro, G. Geometrical SAR image registration. IEEE Trans. Geosci. Remote Sens. 2006, 44, 2861-2870. [CrossRef]

29. Wang, T.; Jonsson, S.; Hanssen, R.F. Improved SAR Image Coregistration Using Pixel-Offset Series. IEEE Geosci. Remote Sens. Lett. 2014, 11, 1465-1469. [CrossRef]

30. Bamler, R.; Eineder, M. Accuracy of differential shift estimation by correlation and split-bandwidth interferometry for wideband and delta-k SAR systems. IEEE Geosci. Remote Sens. Lett. 2005, 2, 151-155. [CrossRef]

31. Zan, F.D. Coherent Shift Estimation for Stacks of SAR Images. IEEE Geosci. Remote Sens. Lett. 2011, 8, 1095-1099. [CrossRef]

32. Hooper, A.; Zebker, H.A. Phase unwrapping in three dimensions with application to InSAR time series. J. Opt. Soc. Am. A 2007, 24, 2737-2747. [CrossRef]

33. Stein, S. Algorithms for ambiguity function processing. IEEE Trans. Acoust. Speech Signal Process. 1981, 29, 588-599. [CrossRef]

34. Shi, X.; Zhang, L.; Tang, M.; Li, M.; Liao, M. Investigating a reservoir bank slope displacement history with multi-frequency satellite SAR data. Landslides 2017. [CrossRef] 